\title{
Design Optimisation of Marine Wastewater Outfalls
}

\author{
Shaun Forrest*, and Rabee Rustum \\ Institute of Infrastructure and Environment, Heriot-Watt University, Dubai, UAE
}

\begin{abstract}
This work presents a method that optimises the manifold pipe of a marine wastewater outfall under various hydraulic principles and cost considerations. Costing data from 37 international pipe supply companies providing pipes of various diameters for HDPE, steel and concrete were used to develop hybrid design equations for these three main materials used for outfall construction. These equations optimise the trade-off between pumping head and pipe size as well as the compromise between cost of material and favourable hydraulic characteristics. Various grades for each material were considered if relevant to marine outfalls. The resulting equations are very useful for outfall design, as oversizing of a project can incur unnecessary cost and under-sizing will not fulfil an outfall's intended hydraulic purpose and will increase the operational cost in terms of energy.
\end{abstract}

\section{Introduction}

With global population increasing at unprecedented rates coupled with the effects of climate change, wastewater volumes will consequently increase, leading to a need for effective disposal options. Marine wastewater outfalls provide a solution to this; though effectively managing the cost and design of these outfalls are imperative.

An ocean outfall is defined by Mendonça et. al (2012) as "a set of hydraulic structures between dry land and receiving water body which waste effluent is finally discharged." An outfall consists of three main components including an onshore headwork, a feeder pipeline and a diffuser section. The onshore headwork may include pumping stations or the use of gravity to convey the effluent to the feeder pipe. The diffuser section is a set of ports whereby effluent is released into the marine environment and dispersed so as to minimize any impairment to the quality of receiving waters. Effluent transported in the pipe to the disposal point generally originates from a wastewater treatment plant which treats municipal, industrial and urban runoff wastewater.

The main objectives for outfall design can be categorized into three main factors, namely hydraulic design factors, design life factors and design factors relating to impact on the marine environment.

Design considerations in combination with construction and installation techniques are important to determine suitable optimization techniques and methods that can be applied to marine wastewater outfalls. Once the appropriate location has been selected, hydraulic design elements become the most important part for the design process (Daymond, 1940).

This paper explores Hydraulic design and its optimisation, as once the outfall position had been determined, the main considerations become almost entirely hydraulic focused factors (Daymond, 1940).

Hydraulic design factors can be summarised into the following design objectives:

- A uniform flow distribution should be maintained through the riser and diffuser section of the outfall.

- Initial dilution should be maximised, or at least maintained at the required legislation stipulated by the governing body over the marine area.

- Internal head losses should be minimised throughout the outfall.

- Sedimentation and saline intrusion inside the outfall should be avoided.

- Scour and sedimentation surrounding the outfall should be avoided.

${ }^{*}$ Corresponding author

Email: shaunforrest@gmail.com

(C) 2016 International Association for Sharing Knowledge and Sustainability

DOI: $10.5383 /$ swes.8.01.003 
This brings into consideration that solely focusing on the price of a pipe or pipeline does not reflect other important factors such as hydraulic influences in the design stage of the marine wastewater discharge pipe (MWWD).

For example, one must consider the compromise between the size of the outfall pipe and its effect on the pumping head. This leads to the importance of accounting for trade-offs in relation to cost parameters, in order to effectively optimise the design of the MWWD. Cost parameters represent the capital and operational costs; and when considering these factors as part of the hydraulic design, a balance can be attained to find an optimal pipe size at an optimal cost. Therefore, optimisation means finding optimal pipe diameters for flow using parameters such as pipe length and material, including the associated roughness of the pipes. Thus, considering these factors, a calculated optimal diameter would represent an optimal cost for the project ( El-Mahdy et. al, 2010).

This work aims to consider hydraulic factors of a MWWD and combine it with pipe capital cost and operation costs to develop useable equations to reach an optimal pipe diameter that gives an optimal price consideration for the design. The primary focus for the research and analysis is based on the manifold section; hence it will not include optimisation of the diffuser and drop-shaft components of an outfall.

\section{Outfall Cost Considerations}

As previously mentioned, the cost optimization of the manifold section of a MWWD is specifically analyzed. This does not discount the importance of the cost of pumping the wastewater, which can also be influenced by factors such as pipe materials and pumping head. However the cost of the manifold pipe, $\mathrm{C} \_\mathrm{m}$ is the variable examined and optimized in this paper.

C_ $\mathrm{m}$ is dependent on the relationship between the pipeline length, L and diameter, D. Equation 1 highlights this relationship.

$$
\text { C_m }=\mathrm{k} \_\mathrm{m} \mathrm{LD} \mathrm{D}^{\wedge} \mathrm{m}
$$

where $\mathrm{C}_{-} \mathrm{m}$ is the cost of the manifold pipe, $\mathrm{k} \_\mathrm{m}$ is a coefficient and $\mathrm{m}$ is an exponent. These variables are dependent on the outfall material, monetary cost of each unit and economic factors. Figure 2 represents a simple relationship between cost and diameter of a HDPE pipe (Georg Fischer, 2013), where the relationship is used to obtain C_m.

Graphs may be plotted by using the relationship between pipe cost and diameter, for each pipe material to get an overall estimate of $\mathrm{C}_{-} \mathrm{m}$ as a preliminary design tool.

As wastewater outfalls generally employ a pumping main, the goal of optimization for the outfall is the determination of an optimal sized D with various hydraulic components. The following is a process to determine the optimal diameter (D) for a marine wastewater outfall.

Pumping main average velocity has been suggested at $0.6 \mathrm{~m} / \mathrm{s}$ (Thresh, 1901) and no greater than $0.75 \mathrm{~m} / \mathrm{s}$. For maximum Q pumped, the pumping main $\mathrm{D}$ is represented by Equation 2 (SI units).

$$
\mathrm{D}=\mathrm{k} \sqrt{\mathrm{Q}} \text { where } 1.3 \leq \mathrm{k} \leq 1.46
$$

or k stipulated by the Lea formula (Garg, 1990) as highlighted by Equation 3 .

$$
0.97 \leq \mathrm{k} \leq 1.22
$$

Figure 2 represents a schematic diagram of a pumping main and Equation 4 is objective function to be minimized for this pumping main

$$
\mathrm{F}=\mathrm{k} \_\mathrm{m} \text { LD }{ }^{\wedge} \mathrm{m}+\mathrm{k} \_\mathrm{T} \text { pgQh_0 }
$$

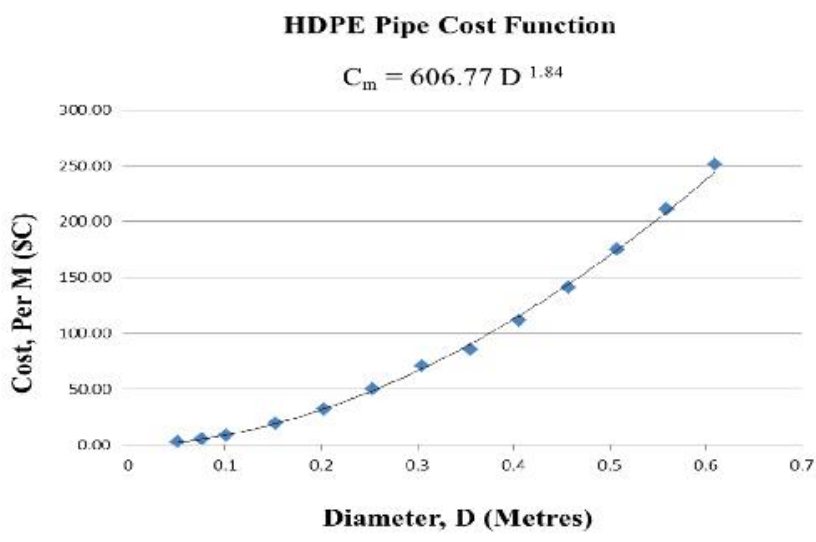

Figure 1 Relationship between HDPE Pipe Cost and Diameter (Georg Fischer, 2013)

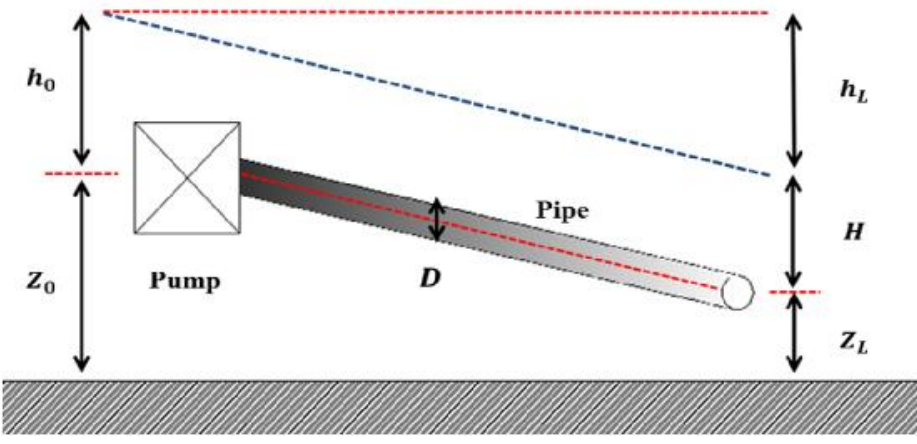

Figure 2 Schematic Representation of a Pumping Main

Now one must consider the hydraulic constraints that have to be satisfied. Equation 5 is a representation of this.

$\frac{8 f L Q^{2}}{\pi^{2} g D^{5}}-h_{0}-z_{0}+H+z_{L}=0$

One may now add the Lagrange multiplier, $\lambda$, for optimisation. As a consequence, a merit function $F_{1}$ is obtained (Prabhata et. al, 2008), through Equation 6.

$F_{1}=k_{m} L D^{m}+k_{T} p g Q h_{0}+\lambda\left(\frac{8 f L Q^{2}}{\pi^{2} g D^{5}}-h_{0}-z_{0}+H+z_{L}\right)$

With respect to $D$, ho, and $\lambda$, the partial derivative of $\mathrm{F}_{1}$ should be zero for optimal design purposes. For outfall design and calculating the optimal $D,\left(D^{*}\right)$ of the wastewater pipe, two methods may be adopted, namely the iterative design procedure or the explicit design procedure. The explicit design procedure is chosen for easier calculation over the various iterations of the second method. 
The explicit design procedure (Prabhata et. al, 2008), does not use an iterative function while solving for $D^{*}$. This method begins by cancelling $f$ from Equation 5, with the constraint equation reduced and represented by Equation 7 .

$z_{0}+h_{0}-H-z_{L}-1.074 \frac{L Q^{2}}{g D^{5}}\left\{\operatorname{In}\left[\frac{\varepsilon}{3.7 D}+4.618\left(\frac{v D}{Q}\right)^{0.9}\right]\right\}^{2}=0$

The relationship between $D^{*}$ and the entry variables may yield an empirical equation acquired through curve fitting and denoted by Equation 8 .

$$
D^{*}=\left\lceil\left(0.591 \frac{k_{T} \rho Q^{3} \varepsilon^{0.263}}{m k_{m}}\right)^{\frac{40}{m+5.26}}+\left.\left(0.652 \frac{k_{T} \rho Q^{2.81} v^{0.192}}{m k_{m}}\right)^{\frac{40}{m+4.81}}\right|^{0.025}\right.
$$

Equation 8 may be reduced by using $v=0$ for a turbulent rough flow highlighted by Equation 9 or using $\varepsilon=0$ and reducing to Equation 10.

$D^{*}=\left(0.591 \frac{k_{T} \rho Q^{3} \varepsilon^{0.263}}{m k_{n}}\right)^{-\frac{40}{m+5.26}}$.

$$
D^{*}=\left(0.652 \frac{k_{T} \rho Q^{2.81} v^{0.192}}{m k_{n}}\right)^{\frac{40}{m+4.81}}
$$

Taking $D^{*}$ from Equation 8 and entering it into Equation $7, h_{0}^{*}$ can be obtained. Now with $D^{*}$ and $h_{0}^{*}$ obtained, F may be calculated through Equation 6. These equations become the basis for optimising the manifold section of a MWWD. However, the main challenge is to determine the coefficients of these equations which will be discussed further.

\section{Data}

Data used in this study were obtained through 37 different pipe supply companies (a full list of company and pricing information can be found in Forrest, 2013). Once pipe pricing information is obtained, it is sorted into pipe grades and diameters and entered into spread sheets. At this point the pricing information is sorted by material type in order for regression analysis to be conducted.

Each company is individually examined by pipe pricing per meter of pipe sold. Pricing structure is converted into U.S.A dollars (\$USD). If companies do not operate in this currency, a conversion is applied.
The currency conversion is applied by the year of sales. In the case of the research only pricing information from 2012 and 2013 is considered as changes in material costs and inflation for example, may skew pricing data greatly if prices are taken before 2012. Once the sale year is established, the yearly average for the conversion currency is established (through Oanda.com) and applied to the yearly average of the \$USD against this currency. The pipe prices are then converted so that all datasets are in \$USD.

Once pricing information is regulated, each company's prices are graphed to show the relationship between price per meter and diameter of the pipe. A regression analysis is then conducted on the data to obtain an equation for this representation and relationship strength in the form of a $\mathrm{R}^{2}$ value. Stronger regressions for each material are highlighted on a graphs to compare each material and their relationships (Forrest, 2013).

Once the strongest relationships for each material are identified, one of the equations derived will be integrated into the hydraulic and cost function equations to provide an example of how to optimise the manifold pipe and develop a rational for calculating an ideal pipe diameter, given the various design inputs available.

\section{Results}

After collection of pipe materials and prices from various companies, one can look to compare the results directly through scaling the $D$ of each pipe material. This is advantageous as some pipe material may only present prices up to a certain diameter. As a consequence, using regression analysis equations, pipe materials can be extended to a common diameter for comparison purposes. Figure 3 highlights this comparison from various companies with stronger regressions.

Figure 3 illustrates that concrete prices are the most consistent and the second most expensive material. However, the exception is one steel company that has slightly more expensive larger diameter pipes. HDPE is the most variable with two of the most expensive pipe companies, but also have some of the cheapest pipes, at a low $D$. This same relationship becomes the second least expensive under a larger $D$. Nevertheless, steel may be considered the least expensive material due to four steel companies pricing structures below all of the concrete companies. Additionally, two HDPE companies exhibit substantially higher pricing structure than the steel companies. All relationships on Figure 3 are power relationships, as all of the polynomial datasets were limited in sample size and $D$ (Forrest, 2013) Figure 3 gives a visual representation of the comparison between the cost and diameter of the various pipe materials. This relationship forms the coefficients required to obtain $D^{*}$ from Equation 8. 


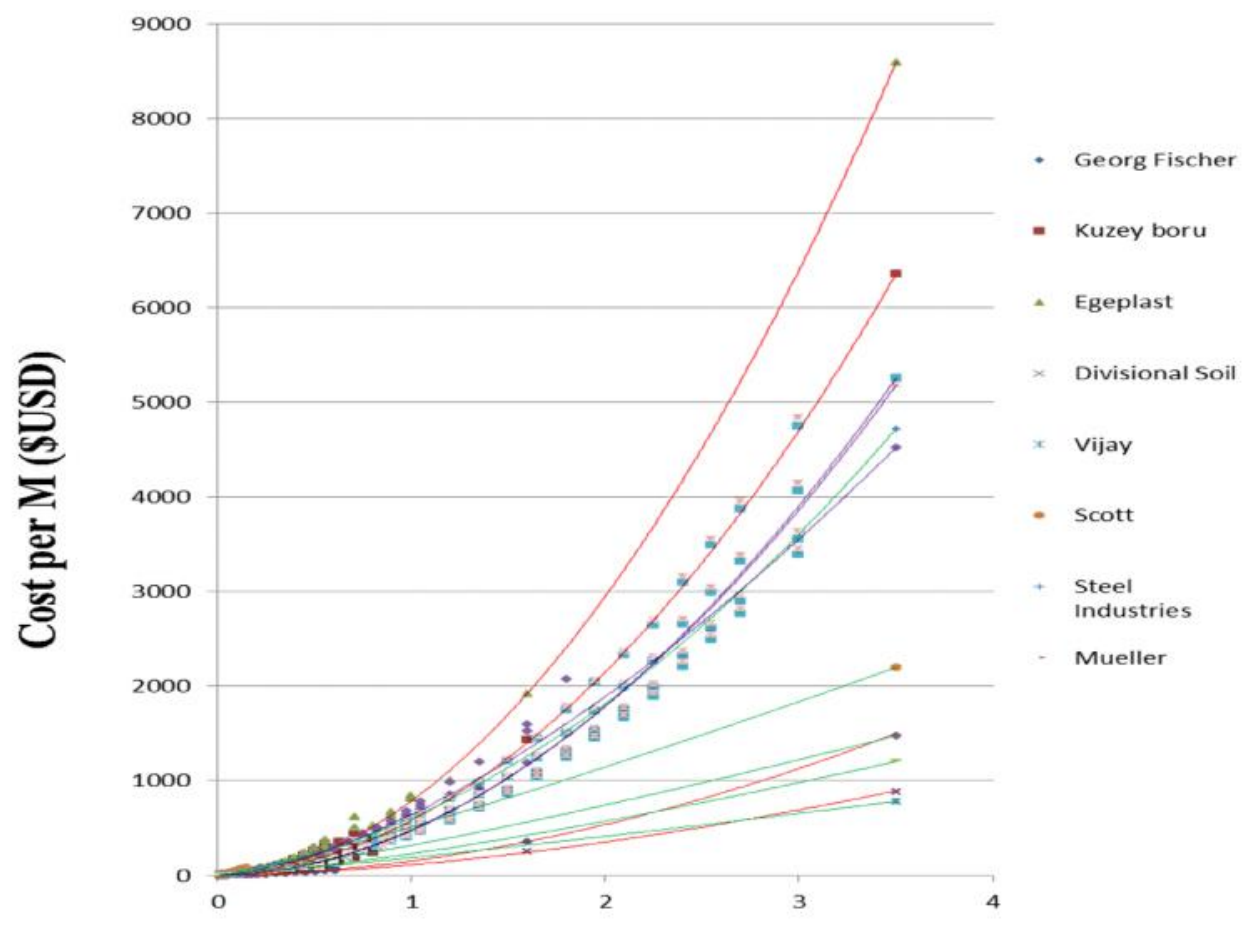

\section{Diameter (M)}

Figure 3 Relationship Comparison between Cost and Diameter of Various HDPE (Red Trend Lines), Concrete (Purple Trend Lines) and Steel (Green Trend Lines) for Various Pipe Supply Companies.

For example, if the relationship for just HDPE pipes are considered, one can look at these relationship examples of a select few companies in Table 1.

At this point a cost function may be developed through the relationships presented to obtain $D^{*}$. For example the equation for Edgeplast, a German company supplying HDPE pipes is chosen and represented by Equation 11.

$C_{m}=785.94 D^{1.9083}$

Using Equation 11 as an example, this may now be substituted into Equation 8 to solve for $\mathrm{F}$ from Equation 4, now represented in Equation 12.

$F=785.94 L D^{1.9083}+k_{T} \rho g h_{0}$.

Combining Equation 12 with Equation 6 yields Equation 13.

$F_{1}=785.94 L D^{1.9083}+k_{T} p g Q h_{0}+$ $\lambda\left(\frac{8 f L Q^{2}}{\pi^{2} g D^{5}}-h_{0}-z_{0}+H+z_{L}\right)$

Now $D^{*}$ can be determined from the explicit procedure underlined in Equation 8. $D^{*}$ may be calculated through Equation 14 (after eliminating $f$ ) by combining Equation 8 and Equation 13.

$$
\begin{aligned}
& D^{*}=\left[\left(0.591 \frac{k_{T} \rho Q^{3} \varepsilon^{0.263}}{1.9083}\right)^{\frac{40}{1.9083+5.26}}+\right. \\
& \left.\left(0.652 \frac{k_{T} \rho Q^{2.81} v^{0.192}}{1.9083}\right)^{\frac{40}{1.9083+4.81}}\right]^{0.025}
\end{aligned}
$$

Roughness heights of materials ( ) will vary, and in this case HDPE can have an assumed of that to PVC at $0.015 \mathrm{~mm}$ (Butler and Pinkerton, 1987; Judd, 2002). Additionally, the kinematic viscosity, $v$, for a rough turbulent flow is assumed to be $10^{-6}$ (though wastewater may present varying $v$ values due to temperature fluctuations). From this point, Equation 8 and Equation 14 may be reduced to Equation 15.

$$
\begin{aligned}
& D^{*}=\left[\left(0.591 \frac{k_{T} \rho Q^{3} 0.000015^{0.263}}{1.9083}\right)^{\frac{40}{1.9083+5.26}}+\right. \\
& \left.\left(0.652 \frac{k_{T} \rho Q^{2.81} 0.000001^{0.192}}{1.9083}\right)^{\frac{40}{1.9083+4.81}}\right]^{0.025}
\end{aligned}
$$

Additionally, $k_{T}$ needs to be determined. The relationship of the optimal diameter and pumping head, $k_{m}$ and $k_{T}$ appear as $k_{m} / k_{T}$ rather than a value representing their absolute magnitude. $k_{p}$ Would have to be calculated separately though the relationship of power and pumping station cost. Knowing $k_{m}$ leads to calculation of $k_{T}$. For the purpose of the current example, $k_{m} / k_{T}$ will be assumed as 0.013 (Prabhata et. al, 
2008 ) in addition to assuming the density of wastewater 1000 $\mathrm{kg} / \mathrm{m}^{3}$

Using the recommended pumping velocity as $0.6 \mathrm{~m} / \mathrm{s}, Q$ may be determined. However, as the $D^{*}$ is being solved by Equation 15, it would be prudent to obtain $Q$ through DWF and a determined factor between 3 and 6 (SEPA 2009). For the purpose of the above example, $Q$ will be $0.25 \mathrm{~m}^{3} / \mathrm{s}$. This reduces Equation 15 to Equation 16.

$$
\begin{aligned}
& D^{*}=\left[\left(0.591 \frac{0.013 \times 1000 \times 0.25^{3} \times 0.000015^{0.263}}{1.9083}\right)^{\frac{40}{1.9083+5.26}}+\right. \\
& \left.\left(0.652 \frac{0.013 \times 1000 \times 0.25^{2.81} \times 0.000001^{0.192}}{1.9083}\right)^{\frac{40}{1.9083+4.81}}\right]^{0.025}
\end{aligned}
$$

Equation 16 yields the answer of 0.5017 , or an optimal diameter of approximately $0.50 \mathrm{~m}$ (with the aforementioned assumptions).

\begin{tabular}{|c|c|c|c|c|}
\hline \multicolumn{5}{|c|}{ HDPE Pipes (PE80 and PE100) } \\
\hline Company & 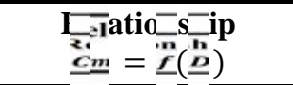 & 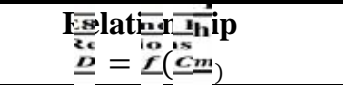 & $\begin{array}{c}\mathbf{R}^{2} \\
\text { Value }\end{array}$ & Comments \\
\hline Georg Fischer & 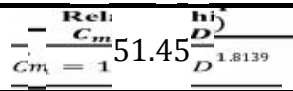 & 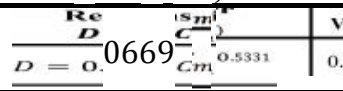 & 0.9805 & USA company. \\
\hline Kuzey boru & $\frac{C-}{C m}=583.43 \frac{D}{D^{1.9059}}$ & $\frac{D=0}{D=0} 0378 \frac{C-}{\mathrm{Cm}^{0.5032}}$ & 0.959 & Turkish company. \\
\hline $\begin{array}{l}\text { Javeri } \\
\text { Investment } \\
\text { CO. }\end{array}$ & $C^{C-}=55^{1.493^{1.2057}}$ & $\begin{array}{l}D=0 . \\
D=0\end{array}{ }^{C-} C^{m}{ }^{\text {o.8169 }}$ & 0.9849 & India company. \\
\hline Egeplast & $\begin{array}{l}C_{-}=5 \\
\bar{C}=7 \\
\end{array}$ & 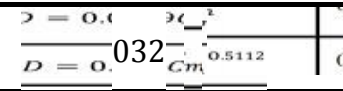 & 0.9755 & German company. \\
\hline TPP & $\frac{1}{\mathrm{C} m=6} 13.2 \frac{1 L}{D^{1.7557}}$ & $\frac{D=0}{D=0} 0285^{\mathrm{Cm}^{\mathrm{o} .5409}}$ & 0.9496 & Thailand company \\
\hline
\end{tabular}

Table 1 Cost and Diameter Relationship for HDPE Pipes from Various Pipe Supply Companies

With $D^{*}$ calculated, it may be used to solve for $h_{0}^{*}$. Subsequently, F may be calculated through Equation 4 .

\section{Discussion}

This work introduced cost considerations for the manifold pipe section of an outfall, stemming from calculations of $C_{m}$, a capital cost in a costing function. However, one must aim to unite recurring cost and capital costs for effective optimisation of the outfall. The development of the cost function in relation to hydraulic principles is related to the relationship of $C_{m}$ and its contribution to the capital cost in the optimisation chart. The explicit design procedure is used in the analysis of a cost function for a MWWD. This is not to discount the iterative procedure, as this too is a viable way of establishing $D^{*}$. However, it is more efficient to present an example from the explicit equations, rather than using an iterative process.

The power function $(m)$ provides the vital input into the cost function equations, which is why a stable power relationship should be established through a dataset with a good range of $D$ information.

The first half of Equation 12 becomes important once $D^{*}$ is calculated and the length of the outfall is known, as it is a function of the price per meter of the pipe. This is where the price of the pipe material becomes important as the equation aims to calculate $\mathrm{F}$ in relation to the pricing information established during the regression analysis. This is not to say that the pipe material is not important in the cost function equations, as an important input to these equations is , which can significantly change $D^{*}$ depending on the material and thus additionally influencing Equation 12. For example if estimated values were used for concrete $(=0.06 \mathrm{~mm})$ and galvanized iron $(=0.15 \mathrm{~mm}) D^{*}$ becomes 0.521 and 0.534 respectively (in

this case just assuming the same power function as HDPE for comparison purposes). Though this may not appear to be a significant difference, it can be substantial for cost; with longer outfalls, the small difference in $D$ would substantially increase the price of the manifold pipe.

The above example highlights the importance of material selection for an outfall, as the most expensive material per meter may actually provide the best hydraulic conditions that in turn affect the cost function. For example, let us consider Equation 11 representing HDPE, Equation 17 representing steel and Equation 18 representing concrete pipes.

$$
\begin{aligned}
& C_{m}=679.93 D^{1.5466} \\
& C_{m}=642.39 D^{1.5576}
\end{aligned}
$$

Integrating each equation into Equation $14, D^{*}$ is calculated to be 0.50 for HDPE, 0.51 for steel and 0.53 for concrete (assuming average for HDPE at $0.015 \mathrm{~mm}$, concrete at $1.5 \mathrm{~mm}$ and $0.45 \mathrm{~mm}$ for steel, Butler and Pinkerton, 1987; Judd, 2002). Adding the $D^{*}$ for each material into the first half of Equation 12 and assuming an outfall length of $1 \mathrm{~km}$, HDPE would equal \$209,379USD, steel \$239,989 and 
concrete $\$ 240,637$ (which would represent the capital cost of the manifold pipe). This presents a significant price difference

between HDPE and concrete, with only a $0.3 \mathrm{~m}$ difference between $D^{*}$. Moreover, this estimation does not include the second part of Equation 12. In the second half of the equation, $h_{0}$ is a component, which is dependent on $h_{f}$ and thus $f$, which is dependent on , stressing the importance of material selection. Nevertheless, in the case of HDPE, Equation 11 displays a larger exponent $(\mathrm{m})$ value as the price increases exponentially faster with an increase in $D$ over other materials. Consequently, if a larger $Q_{D}$ is required, though HDPE has some favourable hydraulic conditions over other materials, it may become a more expensive option.

The examples presented highlight a design trade-off for a MWWD. This includes the compromise between larger pipes and pumping head, where the previous example presented the trade-off between more expensive pipe materials and favourable hydraulic conditions. The equations introduced present a way to quantify these compromises and apply the combination hydraulic analysis and cost functions to optimally design a MWWD, a very useful tool with a growing global population and an increasing reliance on effective wastewater disposal options, such as a marine outfall.

To enhance results from this study, the database used could be developed further through additional research into piping prices and information through more rigorous price sourcing. Moreover, the pipe optimisation may be extended to include the diffuser section and its elements, such as risers and ports, as decisions made in this section of the outfall have a large bearing on cost. Of course with elements such as outfall tapering and various other components incorporated at the diffuser end, more in depth research and calculation would be required, as opposed to just the manifold section. For example, including a $C_{p}$ component, extending through the drop shaft through to the diffuser section, would enhance cost analysis and provide a useful tool in overall outfall cost optimisation

\section{Conclusions}

A cost analysis into pipe material information for marine wastewater discharges established a price per meter to diameter relationship. This cost relationship was applied to cost function equations developed through hydraulic principles and constraints to determine optimal diameters for outfall manifold pipes.

- Cost relationship equations were applied to the explicit design procedure, developed from appropriate hydraulic and cost function equations. The cost relationship equation developed a $k_{m}$ value (a coefficient in an equation solving for $C_{m}$ ) and an $m$ value (an exponent in an equation solving for $C_{m}$ ).

- HDPE equations highlighted $k_{m}$ values, or a base price value lower than some of the other pipe materials. However $m$ values were greater highlighting a steeper exponential curve and thus a greater cost for larger diameter pipes.

- This relationship for HDPE is important, as optimizations attempts to find the optimal diameter which satisfies a variety of capital and operation costs under hydraulic constraints. The equations developed aim to determine the ideal compromise between HDPE's greater costs with larger diameters and its more favourable hydraulic conditions.

- Pipe materials can be compared on the basis of the cost function equations to estimate ideal diameters and thus ideal pumping head and their cost function.

- The cost function equations do not consider operational relationships that may also be estimated to enhance optimisation calculations. The function of $k_{T}$ in the cost function equation is developed through the relationship of power and pump/pumping station cost. Additional research may be conducted for pipe optimisation to find this relationship and thus input into cost function equations.

- The research was centred on the manifold pipe of the outfall. Future research could include diffuser and drop shaft pipe calculations to enhance the overall marine wastewater outfall optimisation, in addition to developing a relationship to quantify $k_{T}$.

\section{References}

[1] Butler, D. and Pinkerton, B.R.C. (1987) Gravity Flow Pipe Design Charts. London: Thomas Telford Ltd.

[2] Daymond, J.R. (1940) 'The hydraulic problem concerning the design of sewage storage tanks and sea outfalls', Journal of the Institution of Civil Engineers 13: $217-236$.

[3] El Mahdy, U.F., Ahmed, M.E.H. and Metwalli, S. (2010) 'Computer aided optimisation of natural gas pipe networks using generic algorithm', Applied Soft Computing 10: 1141-1150.

[4] Forrest, S.A. (2013) Marine Wastewater Outfall Design: Cost Considerations and Pipe Optimisation. Saarbrucken, Germany: Lap Lambert Academic Publishing.

[5] Garg, S.K. (1990) Water Supply Engineering. 4th Edition. New York: McGraw Hill.

[6] Georg Fischer (2013) [online] Georg Fischer piping Available

at <http://www.us.piping.georgefischer.com> [Accessed 12th July 2013].

[7] Judd, S. (Ed.) (2002) Process Science and Engineering for Water and Wastewater Treatment. London: IWH Publishing.

[8] Mendonça, A., Losaula, N.M.A., Reis, M.T. and Neves, M.G. (2012) 'Risk assessment in submarine outfall projects. The case of Portugal', Journal of Environmental Management 116: 186-195.

[9] Prabhata, K., Swamee, P.K. and Sharma, A.K. (2008) design of water supply pipe networks. New Jersey: John Wiley and Sons.

[10] Scottish Environmental Protection Agency, SEPA (2009) Regulatory Method (WAT-RM-13) on Microbiological Discharges. Stirling: Scottish Environmental Protection Agency.

[11] Thresh, J.C. (1901) Water and Water Suppliers. London: Rebman. 